\title{
Women and leprosy: a review
}

\begin{abstract}
Summary Gender inequalities in health have a significant impact on women's health. In leprosy gender inequalities could be even more serious, as it is a highly stigmatized disease. A review has been made of the most recent literature dealing with gender and leprosy. First some data are presented on gender inequalities in rates of case detection, deformities and reversal reactions among leprosy patients. Then the major factors contributing to those differences are discussed. The paper ends with some recommendations for further research on gender and leprosy.
\end{abstract}

\section{Introduction}

Women's issues in health have, until recently, received little attention from health managers, policy makers and researchers. ${ }^{1}$ There are, however, many gender inequalities in health which require due attention in health planning and management. Gender refers not only to sex, but also to the wide variety of social, cultural and economical variables attributed by social structures to men and women. ${ }^{2}$ Men and women experience differential health risks stemming from their social roles and expectations. Women may have a different exposure to disease and infection, and diseases may have a different impact on women, not only in a medical sense, but also in sociocultural and economical ways. Some diseases affect women particularly or exclusively, such as reproductive health problems, and cervical and breast cancer. Other diseases affect both men and women, but have a different impact on wome such as nutritional morbidity, sexually transmitted diseases (STDs) and pelvic infections, and some tropical diseases such as malaria, schistosomiasis and tuberculosis. ${ }^{3}$ Information on how women are affected differently is, however, still limited. Women may have less access to health services than men, they maybe treated differently to men, and diseases may manifest themselves differently in women, requiring a different treatment approach.

\section{Gender and leprosy}

In some tropical diseases, such as filariasis, and leprosy, gender inequalities may play an even larger role, because of their effect on physical appearance and the social stigma associated with them. ${ }^{1}$ Although worldwide the number of registered leprosy cases has been reduced enormously in the past ten years, leprosy is still endemic in many countries in the world. The global registered prevalence was 1.7 per 10.000 in $1996 .{ }^{4}$ There is probably a wide difference between the registered and the actual number of leprosy cases. Also treatment defaulting is still a problem; On average $5-20 \%$ of the patients do not complete their treatment and may thus remain a potential source of infection. Leprosy is therefore expected to remain a public 
health problem for at least the next decade. What is more, considerable differences exist in the registered incidence (case detection) rates of leprosy between the two sexes. Sex differences are also observed in the prevalence rates of deformities and reversal reactions due to leprosy.

\section{GENDER DIFFERENCE IN CASE-DETECTION RATES}

Worldwide, case-detection rates of leprosy vary considerably for men and women. In most areas of the world case detection rates are higher among men than women, at least in its clinical forms, at a ratio of $2: 1$. Already 50 years ago, studies in the Philippines, South India and Norway found that leprosy case-detection rates in males exceeded that in females, at least among adults. ${ }^{5}$ More recent studies in Asia still find a similar difference in case detection rates between men and women: e.g. in rural Nepal sex ratios of $3: 1$ and $1 \cdot 66: 1$ were found in 1982 and 1994 respectively, ${ }^{6,7}$ and in Bhutan, these figures varied between $1 \cdot 4: 1$ and 3·8:1. Also in several African countries (Senegal, Morocco and Tunisia), the male/female rtio varies between $1 \cdot 5: 1$ and $2: 1 .^{9,10}$

There is however an important exception to the above noted sex ratios. In some African countries the case detection rates are similar for men and women, or even higher for women. In Kenya, for example, the male : female rates are similar $(1: 1),{ }^{11}$ while in Burkina Faso the male : female ratio is $1: 1 \cdot 5 .^{12}$ Also Uganda and Malawi have a higher prevalence of leprosy among women. ${ }^{13,14}$

\section{GENDER DIFFERENCE IN DEFORMITY RATES}

The epidemiology of deformities in leprosy has received little attention, but some data demonstrate significant differences in the frequency and types of deformities among each sex. ${ }^{15}$ A study in India revealed that the incidence of deformities in males was more than twice as much as in females for grade I as well as grade II deformities $(n=2285) .{ }^{16,17}$ Studies in Burkina Faso, Venezuela, Nigeria, Malawi and China reported similar findings. ${ }^{12,15,18,19,20}$

\section{GENDER DIFFERENCE IN REVERSAL REACTIONS}

Another finding is that, despite a predominance of men among leprosy patients, reversal reactions are more common among women: In Thailand, for example, reversal reactions occurred with significant greater frequency in women (47\% against $26 \%$ ) and did not appear to be influenced by age of onset of leprosy (cohort study, $n=176) .^{21}$

The above data on sex differences in case-detection rates, deformity rates and reversal reactions suggest that men and women run indeed differential risk for leprosy and/or possibly do not have equal access to leprosy health services. In the sections below, some of the major factors which could influence gender differences are examined for different aspects of leprosy and leprosy health services: exposure to disease, utilization of health services, case-detection methods, treatment compliance, and outcome of the disease. The focus will be on the most commonly observed gender difference in leprosy, i.e. that leprosy case-detection rates are higher for men than for women in most countries.

\section{Exposure to disease}

Gender differences in exposure to disease could have a biological as well as a sociocultural 
background. A biological factor which may influence gender differences in the incidence of leprosy is immunological. The main social factors influencing differences in exposure to leprosy are occupation and socioeconomic status.

\section{IMMUNOLOGICAL REACTIONS}

Women appear to develop stronger and possibly more effective immune reactions against infection with Mycobacterium leprae in a subclinical setting than men. ${ }^{16}$ This immunological response is not limited to $M$. leprae, but is also presents for diseases, such as tuberculosis.

In pregnancy, the immunological response is suppressed. The effects of pregnancy and lactation have been studied in detail in Ethiopia, where a diminished and unstable immune response was found among 114 pregnant leprosy patients. ${ }^{22}$ Pregnant women also had a higher risk of development of neuritis, ${ }^{23}$ and relapse, although relapse rates are usually higher among men. ${ }^{24}$ Another study found that adolescent girls have an increased risk of relapse of leprosy, compared to men of the same age. ${ }^{25}$

\section{OCCUPATION}

In many countries much of women's work is within the household. This might reduce their risk of infection. In Brazil, case detection of leprosy among women has been increasing since women started working outside the home and is now $1: 1$ for men and women. ${ }^{26}$ On the other hand, if women stay indoors most of the time, their health problems may remain longer undetected. In general, it is assumed that risk and prevalence of infection among women is underestimated. ${ }^{2}$

\section{SOCIOECONOMIC STATUS}

Socioeconomic status is also recognized as a major determinant of exposure to disease risks. A leprosy study in Venezuela found a six times higher prevalence in areas of low economic development compared with areas of highest level (1.91 versus $0 \cdot 3$ per 1000$)$, and an almost double incidence (3.39 versus 1.97 per 100.000). ${ }^{27}$ About $75 \%$ of cases of leprosy among 8608 women were associated with low standards of living with regard to economic status, cultural level, nutrition, hygiene, and living quarters. A study in India found that the proportion of illiterate and unemployed female leprosy patients is considerably higher (74\% versus $44 \%$ and $51 \%$ versus $25 \%$ respectively). ${ }^{28}$ Few analytical and sociological studies have assessed these factors in detail.

\section{Utilization of health services}

The observed gender differences in case-detection rates could be due to women having less access to and making less use of health services. Several studies on gender differences in utilisation of health services, show that women have less access to health services than men. ${ }^{29}$ Women's access to health services is influenced by many factors, including availability of services, costs, quality of care, social structure, and women's decision making power.

Availability of services: India study found that detection rates were similar for both sexes in urban areas $(1: 0 \cdot 9)$, but differed widely in rural $(1: 0 \cdot 7)$ and tribal areas $(1: 0 \cdot 6)$. These differences were probably related to lower coverage in those areas. ${ }^{41}$ 
Awareness/literacy: The same study, and other studies noted that women were generally less aware than men of the symptoms of leprosy and the availability of leprosy services. ${ }^{30,31,41}$ In Nigeria, the spouse is the most important source of information for women about leprosy (30\%). Only $22 \%$ of women get information from health workers, compared with $43 \%$ of the men. ${ }^{32}$

Decision making power: In many countries women;'s access to health care is determined by their status within the family. In India, the decision to call a doctor is generally taken by men or the mother-in-law. A married women often delays seeking treatment because of the husband's apathy or because of jealousy of the mother-in-law. ${ }^{33}$ Similar lack of decisionmaking power for women is found in many other countries in Asia, Africa and Latin America. $^{3}$

Mobility of women: Women's mobility is not only limited by lack of decision making power, but also by lack of time and money, their unwillingness to disrupt household duties or their inability to find other caretakers for their children. Women tend to be the main health provider for their families, and as such suffer greatest impact of diseases. They often have to carry the additional burden of caring for other members when ill. $^{34}$ The family has a considerable role in determining when women seek health. In India, the gap between noticing a symptom and suspecting it to be leprosy, as well as the gap between the suspicion and seeking medical confirmation was considerable longer for women than men (16 versus 11 months and 15 vs 10 months). ${ }^{35}$ Similar findings were noted in another study in India (31 months delay in detection $v s 17$ months delay for men). ${ }^{28}$

While these factors are not specific for utilization of leprosy services, it affects leprosy patients more seriously due to the long duration of the treatment involved.

Quality of services: Women's access to and utilization of health services will also depend on the perceived quality of these services. It has been widely recognised that women are hesitant to seek treatment because they feel treated in an inferior way by health services. ${ }^{1}$ In many countries, particularly Islamic countries, women are not allowed to be examined physically by men, although male staff predominate. In India, most leprosy clinics have only male staff.

Stigma: Finally, stigma attached to a disease may also be a serious barrier to seek medical care. Women might delay seeking medical care when they suspect having leprosy, since being diagnosed with leprosy might severely reduce their chances of marriage or may affect their position and role in the household when married. In Nepal, fear of stigmatization was found to be an important reason for some ethnic groups patients to visit treatment centres far from home. ${ }^{42}$ The percentage of leprosy patients hiding their symptoms is smaller than previously, but still considerable. A study in India found that $18 \%$ of women were hiding their symptoms, ${ }^{37}$ and another Indian study found that that women tend to hide more than men (26 versus $21 \%)^{28}$

Studies in Thailand and the Philippines on the stigma of leprosy showed that stigma is still an important barrier to the seeking of timely treatment. ${ }^{38,39}$

\section{Case detection methods}

Even if women have the same risk as men for infection with leprosy, and have equal access to and make equal use of health services as men, still a difference in case detection may occur due to gender insensitivity of the methods used for case detection.

In India, lower detection among females than males was observed in various modes of 
detection: more women were detected in general surveys and contact surveys, while fewer women were detected by referral, voluntary reporting and school surveys. ${ }^{40}$ The same study also noted that the proportion of voluntarily reporting among women is less than among men.

Passive case detection rates could also result in significant differences in rates per age group: A study in India found that the percentage of passively detected girls in the puberty age group (11-17 years) is almost half of that of boys of the same age (13\% vs 24\%), while in the age group 18-35, female case detection rates are higher than men of the same age group (32\% vs 25\%). ${ }^{40}$ The association of low case detection with a specific age group could be related to religious and cultural taboos, i.e. girls and women who are not yet married are not allowed to show their body to male health staff and hence are not visiting health services and/ or are not properly examined and diagnosed.

\section{Treatment compliance}

Gender differences may also exist in treatment compliance. Studies in Pakistan and India found that women are generally more compliant than men (95\% vs $83 \%$ in India). ${ }^{40,41}$ This was attributed to women being more socialized to conform to prescribed behaviour. Compliance can however be influenced by socialcultural perceptions and beliefs. Some traditional medical practices attribute the cause of illness to behavioural lapses by women, preventing them from obtaining prompt treatment and continuing adequate treatment. ${ }^{3}$ Leprosy is believed to be the wrath of God, resulting in women delaying taking treatment until measures such as fasting and offerings had been made (18\% of women compared to $6 \%$ of men did so). ${ }^{35}$ In India, many women, after being diagnosed with leprosy, and despite MDT, continued to rely on religious and traditional sources. In leprosy colonies $10 \%$ of women did not take any treatment despite their awareness of the disease. ${ }^{35}$

Women could also be hesitant to take leprosy medication for different reasons, such as the perceived effects of the drugs: Rifampicin, one of the MDT drugs for leprosy, turns the urine dark. Many women were concerned about this side effect of the drug, as the change of colour is associated with jaundice, which is considered one of the deadliest diseases. Some women consulted a 'jaundice expert' and stopped taking treatment on his advice. This study from Pakistan, included only women, and did not report whether the same fear was present in men. ${ }^{41}$ This study found that the dark skin coloration associated with Clofazimine, is a big problem for many women as a dark skin is often associated with lower social status. ${ }^{41}$

Furthermore, the Dapsone, causes problems as it looks similar to a popular brand of contraceptive pill (Mala D.) When provided in blister packs it resembles "the pill" even more. Health workers frequently face a mother-in-law who forbade her daughter-in-law to take MDT for this reason.

In Nepal, treatment compliance was also found to be related to the quality of the services. $^{42}$

It is not known to what extent these examples of poor compliance have a negative impact on the outcome of leprosy treatment.

\section{Outcome of disease}

Outcome of disease can be measured both in medical and sociocultural terms: the consequences of leprosy could be different grades of deformities and disabilities, but also 
social isolation or expulsion of the women from the family. Significant differences exist in disease outcome, deformities being more common among men than women. A biological explanation for this difference could be the fact that multibacillary (MB) leprosy, which involves an increased risk of deformities, is more common among men: in Venezuela and Ethiopia, a predominance of MB leprosy was found among men compared to women $(2 \cdot 5: 1$ in both countries). ${ }^{15,43}$ The incidence of disabilities and deformities are found to be associated not only with sex and the type of disease (MB or $\mathrm{PB}$ ), but also with nerve trunk involvement and the duration of the disease. ${ }^{44,45}$

A sociocultural explanation for the observed gender difference could be different occupations between men and women: Two studies attributed the gender difference in incidence of deformities to men working outdoors involving both hand and feet. ${ }^{16,17}$ In India, men were found to be more affected by their feet, while women suffered more leprosy associated injuries on their hands. Feet are more vulnerable in agricultural and other outdoor occupations while hands are more exposed in indoor occupations. In many cultures, however, women also do much of the outdoor work, fetching fire wood and water, working on the fields, and are on their feet all day.

Considering sociocultural outcome of disease, several studies indicate that women are more affected by leprosy. They suffer more isolation, rejection from spouses, children and relatives, loss of freedom to touch and have more restrictions than men in India. ${ }^{40}$ Women with leprosy are less likely to have the opportunity to marry. ${ }^{46}$ In Brazil, women tend to remain single, separated or widowed, live with relatives or with their children without their spouse, and indicate leprosy as a reason for family separation. ${ }^{26}$

\section{Discussion}

The review of studies shows that there are many gender differences, biological as well as sociocul tural, which are related to leprosy. Data are, however, not uniform. Case-detection ratios of leprosy vary considerably, not only for the two sexes, but also per country, per socioeconomic group, per age group, and over different time periods. An important obstacle in analysing gender differences in case detection ratios is that routine data collected on case detection are not desegregated for sex. The available data on sex differences in case detection are too scanty and too diverse in geography to compare. A complicating factor is that case detection rates can vary considerably over time, even within a country, depending on the methods of case detection that have been used. Active case finding in India, involving among others house-to-house surveys carried out by scouts or school girls resulted in a large increase in case-detection rates over the past few years. ${ }^{47}$

It will therefore be hard to explain why sex differences in case detection exist within a country, or between countries in the same continent, let alone that any explanation can be given for the reverse situation which is found in some African countries. There is, however, a strong indication that sex differences in case detection are significant, and further research is needed to quantify and to explain these differences, and to know whether they are mainly sex or gender related or whether a combination of both groups of factors plays a role. In order to compare data on case detection from different countries, multicentre studies are required, using a standard research methodology, and using the same methods for case detection.

Even more important than knowing whether gender differences in case detection ratios are significant is to understand the factors contributing to the observed differences. The wide 
variety of potential variables, biological as well as sociocultural, with sometimes contrasting data makes it difficult to establish the major contributing factors to observed differences. Existing data are too scanty to draw any conclusions.

The review of the available literature on gender issues related to leprosy reveals that many biological as well as sociocultural factors play a role in the lower case detection rate among women. More research is needed to determine the relative importance of the different groups of factors: biological, health services or community related. Within each group, again more insight is needed on the major factors contributing to gender inequalities in order to address these problems. How can health services be improved to increase their utilization by women? How can health education messages be improved to reach the high risk groups among women? Qualitative, comparative research will be needed to address these questions.

It should be noted that most studies on leprosy included in this review are from Asia and Latin America, while few studies were found from Africa. If the gender differences as observed in most countries are indeed significant, it would be interesting to know why some African countries show a different picture. Again, qualitative, comparative studies will be needed to explain these differences.

\section{Acknowledgments}

This article has been based on a literature review made for a research proposal on gender differences in case detection in selected countries, which was developed at the initiative of Netherlands Leprosy Relief Foundation (NSL), Amsterdam. I wish to thank Henk Egbers, Peter Lever and Anita Hardon for their comments on an earlier version of the literature review.

clo J. Wittenberg

AMANDA LE GRAND

National Museums of Kenya,

PO Box 40658

Nairobi, Kenya

\section{References}

1 Vlassoff C. Gender inequalities in health in the third world: uncharted ground. Soc Sci Med, 1994; 37: 1249-1259.

2 Rathgeber EM, Vlassoff C. Gender and tropical diseases: a new research focus. Soc Sci Med, 1993; 37: 513520 .

${ }^{3}$ Okojie CEE. Gender inequalities of health in the third world. Soc Sci Med, 1994; 39: 1237-1247.

${ }^{4}$ WHO. Weekly Epidemiological Record. Geneva, May 1996.

5 Scollard DM, Smith T, Bhoopat L, Theetranont C, Rangdaeng S, Morens DM. Epidemiologic characteristics of leprosy reactions. Int J Lepr, 1994; 62: 559-567.

6 Pearson M. Social factors and leprosy in Lamjung, West Central Nepal: implications for disease control. Ecol Dis, 1982; 1: 229-236.

7 Theuvenet WJ, Soares D, Baral JP, Theuvenet-Schutte AR, Palla JP, Jesudan K, Nakami J, Bista RB, Jayakumar P, Failbus PK. Mass survey of leprosy in Lalitpur district, Nepal. Int J Lepr, 1995; 62: 256-262.

8 Jakeman P, Jakeman NRP, Singay J. Trends in leprosy in the Kingdom of Bhutan, 1982-1992. Lepr Rev, 1995; 66: 64-75.

9 Millan J, Bodian M. La lutte contre la lèpre en mileu urban africain: problèmes rencontrés au niveau de dépistage et du contrôle des malades à Dakar. Acta Lepro, 1986; IV, (1): 5-17.

10 Acta Lepro, 1986; IV.

11 Oral communication of M. van Cleeff, advisor of a leprosy project in Kenya.

12 Tiendrebeogo A, Toure I, Zerbo PJ. A survey of leprosy impairments and disabilities among patients treated by MDT in Burkina Faso. Int J Lepr, 1996; 64. 
${ }^{13}$ Fine PEM. Leprosy: the epidemiology of a slow bacterium. Epidemiolog Rev, 1982; 3: 161.

14 Noordeen SK. The epidemiology of leprosy. In: Leprosy, Hastings RC (eds). p. 15. Churchill Livingstone Edinburgh, 1985.

15 Ulrich M, Zulueta AM, Caceres-Dittmar G, Sampson C, Pinardi ME, Rada EM, Aranzuazu N. Leprosy in women: characteristics and repercussions. Soc Sci Med, 1993; 37: 445-456.

16 Rao SP, Subramanian M, Subramanian G. Deformity incidence in leprosy patients treated with multi drug therapy. Int J Lepr, 1994; 66.

17 Saha SP, Das KK. Disability pattern amongst leprosy cases in an urban area (Calcutta). Ind J Lepr, $1993 ; 65$.

18 Iyere BB. Leprosy deformities: experience in Molai Leprosy Hospital, Maiduguri, Nigeria. Lepr Rev, 1990; 61: 171.

19 Ponnighaus IM, Boerrigter G, Fine PEM, Ponnighaus JM, Russell J. Disabilities in leprosy patients ascertained in a total population survey in Karonga District, Northern Malawi, Lepr Rev, 1990; 61: 366.

20 Guocheng et al. An epidemiological survey of deformities and disabilities among 14.257 cases of leprosy in 11 counties. Lepr Rev, 1993; 64: 143-149.

21 Schollard DM, Smith T, Bhoopat L, Threetranont C, Rangdaeng S, Morens D. Epidemiologic characteristics of leprosy reactions. Int J Lepr, 1994; 62: 559-567.

22 Duncan ME, Meslon R, Pearson JMH, Ridley DS. The association of pregnancy and leprosy I. New cases, relapse of cured patients and deterioration in patients on treatment during pregnancy and lactation-results of a prospective study of 154 pregnancies in 147 Ethiopian women, Lepr Rev, 1981; 52: 245.

23 Duncan E, Pearson, JMH. Neuritis in pregnancy and lactation. Int J Lepr, 1982; 50:(1).

24 Saha SP, Das KK. Study of characteristics and causes of relapse amongst leprosy cases in an urban area. Int J Lepr, 1992; 64:(2).

25 Davey TF, Schenk RR. The endocrines in leprosy. In: Leprosy in theory and practice. Cochrane RG and Davey TF. Bristol: John Wright and Sons, 1964 pp. 190-204.

26 Effects of leprosy on men and women: a gender study. Paper no. 11. Brazil, 1995. Unpublished report available from TDR/WHO.

27 Zuniga M. Avances recientes en la epidemiologia de la lepra. Bol Dermatol Sanit, 1981-1982; 18 : 1.

28 Rao S, Garole V, Walawalkar S, Khot S, Karandikar N. Gender differentials in social impact of leprosy. Aghakar Research Institute Pune, India, Unpublished report, 1996.

29 Santow G. Social roles and physical health: the case of female disadvantage in poor countries. Soc Sci Med, 1995; 40: $147-161$

30 Gender issues in NLEP. Report of a Workshop organized by Danish Assisted National Leprosy Eradication Programme (DANLEP), Tamil Nadu, India. 1995.

31 Crook N, Ramasubban R, Samy A, Singh B. An educational approach to leprosy control: an evaluation of knowledge, attitude and practice in two poor localities in Bombay, India. Lepr Rev, 1991; 62: 395-401.

32 Awof eso N. Effects of socio-cultural beliefs on patients' perceptions of leprosy. Trop Geographical Med, 1995, 47: 175-178.

33 Khan ME, Anker R, Gosh Dastidar SK, Bairathi S. Inequalities between men and women in nutrition and family welfare services. An in-depth enquiry in an Indian village. In: Selected readings in the social cultural and behavioural determinants of health (Caldwell JC and Santow G (eds). Canberra, 1989.

${ }^{34}$ Hibbard JH, Pope CB. Gender roles, illness orientation and use of medical services. Soc Sci Med, 1983; 17: 129137.

35 Vlassoff C, Rao S, Garole V, Karandikar N, Azar M, Kanada A. The family: a neglected determinant of health in South Asia. Unpublished report, TDR/WHO, 1996.

36 Report of a workshop: gender issues in health. Danida Assistance to National Leprosy Eradication Programme (DANLEP), Puri, Orrisa, India, 1995.

37 Vlassoff C, Khot S, Rao S. Double jeopardy: women and leprosy in India/ Forthcoming in: ME Khan (ed). Work, Health and Contraception from women's perspective. Centre for operations Research \& Training, Baroda.

38 Boonmongkon P. Khi thut "The disease of social loathing'": an anthropological study of the stigma of leprosy in rural North-North-East Thailand. Social and Economic Research Project Reports, No 16, UNDP/World Bank/ WHO/TDR 1994.

$39 \mathrm{Paz}$ JC, Medina IR, Ventura ER. A multidisciplinary study of stigma in relation to Hansen's disease among the Tausug in the Philippines. Social and Economic Research Project Reports No. 7. UNDP/World Bank/WHO/TDR.

40 Rao S, Khot S, Walawalkar S, Garole V, Karandikar N. Differences in detection patterns between male and female leprosy patients in Maharashtra. Agharkar Research Institute, Pune India, 1996.

41 Mull JD, Shearwood C, Gans LP, Mull DS. Culture and compliance among leprosy patients in Pakistan. Soc Sci Med, 1989; 29: 799.

42 Pearson M. What does distance matter. Leprosy control in West Nepal. Soc Sci Med, 1988; 26: 25.

43 de Rijk AJ, Gabre S, Byass P, Berhanu T. Field evaluation of WHO/MDT of fixed duration at ALERT, Ethiopia: the AMFES project-1, MDT course completion, case holding and another score for disability grading. Lepr Rev, 1994; 65: 305-319.

44 Noordeen SK, Srinivasan H. Deformity in leprosy: an epidemiological study. Ind J Med Res, 1969; 57: $175-181$. 
45 Ponnighaus et al. Disabilities in leprosy patients ascertained in a total population survey in Karonga district, Northern Malawii. Lepr Rev, 1990; 61: 366-374.

46 Valencia LB. Soci-economic research in the Philippines with special references to leprosy. S.E. Asian Trop Med Pub Hlth, 1983; 14: 29.

47 Project documents from Danida Assistance to National Leprosy Eradication Programme (DANLEP), India 19901996. 